\title{
Understanding the Methodological Process of Formation and Evolution of Scientific Empiricism in the Philosophy of West
}

\author{
Abulqasem Mojtahedi Zanjirabadi ${ }^{1}$, Mohammad Rahim Eyvazi ${ }^{2}$, Reza Jalali ${ }^{3}$, Mahbubeh Pakniya ${ }^{3}$, Hassan Hajizadeh \\ Anari $^{4}$ \\ ${ }^{1} \mathrm{PhD}$ student of Department political science, Islamic Azad Central University, Tehran, Iran \\ ${ }^{2}$ Qazvin Assistant Professor, Department of political science, Islamic Azad University Central Tehran Branch \& Faculty \\ member at International University of Imam Khomeini, Tehran, Iran \\ ${ }^{3}$ Assistant Professor, Department of political science, Islamic Azad University Central Tehran Branch, Tehran, Iran \\ ${ }^{4}$ Assistant Professor, Department of educational science, Farhangian University\& Department of political science, \\ Islamic Azad Central University, Tehran, Iran
}

Correspondence: Hassan Hajizadeh Anari, Assistant Professor, Department of educational science, Farhangian University\& Department of political science, Islamic Azad Central University, Tehran, Iran.

Received: July 18, 2017

doi:10.11114/ijsss.v5i9.2543
Accepted: August 18,2017 Available online: August 25, 2017

URL: https://doi.org/10.11114/ijsss.v5i9.2543

\begin{abstract}
The current paper evaluates the transformation of methodological approaches and perspectives of early centuries of the modern era scientism to fundamental change in the philosophical views of the west in the form of postmodern attitudes. Thus, on the one hand, the evolution in crude empiricism and its transition to positivism, logical positivism and how to transition from positivism to falsifiability will be evaluated. On the other hand, we address the transformation of positivism and falsifiability attitudes and thinking into macro structures and attitudes in the form of Imre and Lakatos research program and Thomas Kuhn's paradigm and finally, Feyerabend anarchist approach. Then, we will continue with a brief overview of how to shape the post-modern approaches as the outcome of fundamental change in the attitude of philosophy in the West. Of course, we try to avoid getting into the details of the views, as far as possible because the main focus of this paper is on the analysis of the evolution of the methodological perspectives of "Scientism (Philosophy of science)" to postmodernism.
\end{abstract}

Keywords: empiricism, positivism, logical positivism, falsifiability, the research program, paradigm, incommensurability

\section{Introduction}

Modern times in Europe started in the sixteen and seventeen centuries with a fundamental revolution in the views and beliefs of European thought. European modernity was a turn in the European classical times formulated views and opinions. Western modernity begins the Enlightenment. Enlightenment included intellectual movement and socio-cultural and political movement with faith in reason as the key to knowledge, understanding and human progress.

The concept of religious tolerance and combating all forms of fanaticism its main focus (Nozari, 1979: 49). In fact, two major schools of philosophical thought formed in the modernity era in the West, one was the rational school of thought pioneered by Rene Descartes, the French philosopher, the trend continued by writers and philosophers like Spinoza, Leibniz, Kant, Goethe, Schiller, and other rationalist scholars. Empiricism was one of the trends of the era shaped following the importance of science started with the crude empiricism of early centuries of the early 16th and 17th centuries of modernity leading to positivism and logical positivism and their critics. A group of scholars believed that ideas come to us from outside and the mind is like a white page and experience writes new things on it. Others believe that ides are innate with human mind as the repository of meanings and the outside world merely evokes sensations and experiences already existed in the mind of the initial state. The first group is known as sensualists and empiricists and the second group is spiritualistic, the originality of thought or rationalism.

Distinction between the two is that the first group believes in a posteriori ideas and the second group believes in innate ideas or a priori ideas (Corner, 1988: 27 and 28). The current paper aims to analyze and portray the transformation and evolution of the first school. 


\section{Evolution and Development from Empiricism to Relativism}

We should refer to prevailing Ontology and epistemology on the trend of transformation from empiricism to relativism to understand the features and views influenced by the philosophy of empiricism in the west. Moreover, we should review the literature in this regard. Ontologically, the modern time in west thought starts with the effects of natural sciences on humanities. The prominent perspective in the early period of Western modernity is "empiricism". Therefore, we try to draw prospects in the process of transformation of empiricism. The scientific revolution in different areas of human life started with progress in the natural and experimental sciences in the seventeenth century, with effects extended to the realm of thought and philosophy. Philosophers like Francis Bacon, Auguste Comte, Alfred Ayer and Carl Hempel affected by these scientific developments were looking to extend this new scientific data in the field of humanities. In the new era what was important was the "science" and scientific attitude prevailed. The science rooted in crude empiricism of early centuries of the modern era called by Francis Bacon as experiments of fruit, he stated: "All research efforts, aimed at specific scientific and eagerly pursued that aim hasty and untimely. I call them "experiments of fruit", not experiments of light. Experiments of fruit are contrary to performance of God who merely created light on the first day of creation and de voted a full day to it. He did not create any of the material on that day, but did it in the following days (Bacon, 1620: 245). The main question of era is: "what is science"? And "what are their Epistemology aspects?" How science can be distinguished from non-scientific? And what are the scientific and non-scientific criteria? Human knowledge is divided into two parts of scientific and non-scientific. Those who had the knowledge found authority and scientists find important high status. Scientific and non-scientific criteria are searched in experience and sense and whatever can be experienced and sensed is scientific. Everything should be observed and whatever observable is real (Chalmers, 2008: 6,7).

In absolute empiricism, the legitimacy of a theory is subject to pass the experimental tests. This criterion is to measure the strengths and weaknesses of the theory. The theory of empiricism, the attitude, the negligence, makes itself the polarization between scientific and non-scientific. As a result, being scientific is the main value (Moeeini Alamdari, 2006: 19). According to empiricism, rationalism, or rather theoretical reason is subject to illusion and wrong. To free the intellect from wandering in vain it should leave behind the world of fantasy and return to experiment ground. Regular testing and accurate registration of the results and the test repeat gives adequate information and enables researchers to enact the laws of intellect. According to the inductively axioms of the constitutive laws are determined and these axioms in turn are subject to further empirical studies. Against Descartes let intellect free to achieve a mathematical certainty, Bacon set experimental certainty (Seyyed Imami, 2008: 6). Following this path, the crude empiricism in Europe, was not merely in search of mere experience, but it should have proven the theory through ontological cases, and the early empiricism of west sought this proof in frequent testing and thus "positivism "is formed; and now experience and experiment together are correct philosophical propositions criterions. In fact, positivism continuing the path that starts with empiricism in the west and puts it one step forward in the course of their transformation. Positivism, with an emphasis on proving theorems and natural phenomenon through repeated testing sought to evaluate claims by early modern era crude empiricism $\left(16^{\text {th }}\right.$ and $17^{\text {th }}$ centuries) which examines knowledge only through observation and empirical phenomena by human senses. The proof of this phenomenon through repeated tests gives positivism consistency and durability. The term positivism as philosophical tendencies first used by Saint-Simon and his pupil Auguste Comte, the founder of modern sociology, in the nineteenth century. Comte like earlier empiricists claimed that philosopher' methods to understand phenomena related to human social life was a wrong approach and new social researches should use scientific methods, which is based on the natural sciences, to study the humanities and social issues. He, in his six-volume book titled "Course" explained his theories on the evolution of the human mind with claims that human thought in the most primitive stage of evolution is essentially theological and then during its development reaches to stages philosophical (metaphysical) and then is scientific. He believes that only in the scientific stage human mind can perceive casual relationships using an appropriate combination of reasoning and observation. Mathematics, astronomy, physics, chemistry and biology expands at scientific stage, and finally expands the social sciences that depart away from philosophy or social philosophy. The social science that ultimately Comte uses the term "sociology" for should follow methodical and epistemological principles of natural sciences in addition benefit for the human species in the functions and ultimately burden a major mission to improve the human life (Coser, 1990: 24). John Stewart expanded Comte view in English language world and then English scientists such as Thomas Huxley and Herbert Spencer proposed ideas in natural sciences methodologies application in new sciences as sociology similar to that of Comet. The tradition of positivism emerged at late nineteenth century clearly continued in the writings of methodology by Emile Durkheim, the French sociologist, on his famous work "Les Regles de la method sociologique "on a regular description (Seyyed Imami, 2008: 14). Logical positivism formed after the positivist approach. Logical positivism is another development in the experimental approach to the phenomena of thought and study based on which in the reasoning in the proof of the theorem, emphasis will be on reasonable evidence in addition to be ing experimental and test capabilities. Logical positivism in continuing the path of western scientism modernity believes that the cases 
are scientific; either proved through experience and testing or evidence of logical sense that it is logically obvious and provable and needs not laboratory approval. Logical positivists claim that the facts and the evidence (visible and measurable) and values (that do not have this capability) are two very separate issues. The sciences and social sciences are increasingly expected to provide us with reliable and valid knowledge. The logical positivists use inductive method and began with details to understand the complexities of the universe and generalize observations to a higher level (Seyyid Imami, 2008: 16). Alfred Ayer, in England and Carl Hempel in Germany argue that social analytical statements about the physical world include one of the following three categories: First, such statements could be beneficial repeated tautology useful in the sense that propositions are merely a special meaning for a particular concept or phenomenon. Second, statements can be experimental; meaning that accuracy can understand through test observations. Third, statements do not fit any of the first and second categories and are with analytical meaning. However, a meaningful analysis can only be based on objective repeated statements include analytical and experience (Marsh and Stoker, 2009: 109). The best-known followers of the positivism in the twentieth century are the Vienna Circle of logical thinkers in the 1920s, Moritz Schlick, Rudolf Carnap, Hahn and Neurath. Limiting knowledge to rational analysis of experimental observations is the main pillar of Vienna Circle relentless attack against metaphysics and theoretical philosophy. They stepped further from the theory of Comet positivism considering it equivalent to empiricism. Direct experience makes possible to formulate sentences that express objective facts with absolute simplicity and without any alterations. Logical positivists apart from statements of logical analysis (mathematics) consider only those statements significant that are based on experience (are authenticated). Hence, the metaphysical statement considered meaningless in the logical positivists system of thought because it is not based on empirical verification condition (Marsh and Stoker, 2009: 15). The most obvious and the most assertive and challenge the doctrine of the logical positivists is the principle of "verifiability" or the recognition. The fate and the future course of logical positivism relied upon the ability to solve problems brought about by principle of verification. The principle status was not yet clear. Because "The meaning of a proposition is the method of its verification" is not a scientific statement. The logical positivists justified this problem that this principle should not be taken as a statements but as a suggestion or recommendation that says that statements should not be accepted as meaningful unless verifiable (Khorram Shahi, 1999: 14). David Hume was the most critical of this approach emphasizing many years ago on the lack of logical connection between the real propositions and value ones. In "A Treatise of Human Nature" Hume (hume, 1888: 469) emphasizes the valid argument should never use preliminary results related to reality and being to reach the values and normative conclusions The fact that is called "Hume's Fork» is the beginning of wide discussion entitled" distinction of is versus ought ", because he insists that it is not reasonably possible to interpreted a value as (both moral and legal) " ought " to deduce from statements about the facts. Requirement and "ought" may not be obtained from "is". So the value, ethical and legal propositions cannot be supported by Epistemology cases, and Factual Premises cannot actually bring results in the wake of values and norms (Vaezi, 2009: 140). Hume draw experimental philosophy to its ultimate logical consequence and, according to Bertrand Russell, he created an impasse in experimental philosophy, to date, despite the efforts of the greatest philosophers have not been opened. Russell claims that it is better to be clearly wrong rather vaguely adopting the correct position; it certainly is the character of Natural Sciences but the social sciences require. Hume agrees with famous predecessor Locke and Berkeley on the origin of mans' imagination and knowledge, namely that is the product of human knowledge and experience, something that he adds and is essential in the history of philosophy, one is the rejection of the concept of substance, especially the "soul" or "self" as substantive and independent and the other is criticism of the concept of causality. In the case of "soul" or "self" Hume argues that when I refer to inner or what is known who "self", I face with the perception of a minor issue such as the cold or the heat or light or shadow or love or hatred or pleasure or pain, and I never can observe myself without any. So he comes to the idea that no one is but a collection of different perceptions that constantly changing in great speed. The result that comes from Hume's argument is that "self" or "soul" is not perceived and is merely a spool of perceptions and discusses it as simple essence is futile, in particular, it cannot be talked about their survival (Corner, 1988: 29). He also believes that the concept of causality is:

Our idea of necessity and causation is directly caused by the evident uniformity and consistency acts of nature where similar issues associated with each, and the habit causes mind conclude one out of the appearance [the advent of] of the other. Besides the permanent consistency of the same issues, thus, to derive one from the other we have no idea of the necessity of connection (Hume, 1888: 92). Hume's arguments weakened inductive authority and, therefore, the foundation of scientific thinking. Clearly, logical positivists could not response to the criticism that has been expressed through the ideas of Hume yet, however in general, regularities in the physical and social world was supposed to be in view of positivism. When the researchers observe an organized phenomenon everywhere with no exceptions, take the order as the Universal Law. But all scientific laws are not universal. Some of the laws rather than claim of all cases of a regular phenomenon merely indicate the percentage of the cases; or based on certain proposition the quantitative relationship with another phenomenon is clarified, that this statement is called statistical law. Statistical laws are the best propositions available where there is no sufficient knowledge to stipulations of a universal law. In the social 
sciences we basically achieve statistical laws rather than universal laws (Seyyed Imami, 2008: 17).

Falsifiability emerged after logical positivism in the west continuing the process of scientific approach. In the eighteenth century, Hume noted that we can ne ver deduce the overall sentence through observations and deductive logic. So no matter how many white swan we see, we can never deduce that all swans are white. Popper in the twentieth century, however, stated that scientific observations and deductive logic though cannot prove the truth of a general rule, can prove its opposite (or falsify it) (Gillis, 2002: 48). Falsification regards science as a set of hypotheses suggested in order to accurately describe and explain the behavior of the temporarily world (Chalmers, 1995: 52). What is important in falsification are guesses that are temporary and are valid as long as they prove or disprove. The guesses are looking to identify the weaknesses of previous theories and in fact falsification is a critical look at the past. Falsification believes science is preceded by theory, but scientific knowledge not only proved through observation and experiment, and basically whatever can be rejected can be proved as well. The certainty opinions on falsification always remain until further notice and subject to the progress of science. Popper believes that the world of science is based on scientific potential problems by eliminating critical solutions. He detects a pattern of three steps for achieving any cognition; first, the mind encounters a problem, then uses different solutions to solve it, and the failed solution are removed one by one. Knowledge progress is possible only through trial and error. Scientists do not start with the observation and then approve hypotheses by inductive inferences and add to their knowledge, but they work by trying to solve the problems. As a result, science constitutes guesses that still have not been rejected, not the facts that are obtained through observation (Popper, 2002).

There is one thing in common between falsification and positivism that is both are specific, in that given basic crude empiricism to Popper's falsification take a look at the phenomena and events all around in specific in search of gradual fractional accumulation of cases. Methods described use "inductive method" but criticism is that they a look at the phenomenon in a particular case can certainly fail it. For example, in the case of falsification a minor case may reject the hypothesis or theory and the criticism is that specifics not to be trusted. The second criticism is that if the observational statement is nor trusted so we never reach certainty. In the transition of these uncertainty and specificity of theories philosophy of science tends to the structural theory. However, this is not the mere lack of attention to these attitudes by a group of thinkers, some other reason that guides modernity to the use of structures is that the scholars believe that the history of science is mainly due to the structures. Structuralists believe the historical review shows the most important evolution, in the realm of structuralism science is clear and falsification escapes it (Chalmers, 1994: 116). Imre Lakatos and Thomas Kuhn are among intellectuals who try to analyze ideas as structures. The main argument is that advancement of science and scientific theories are not obtained through minor statements and in the progress of science must seek for structural and holistic views. And since then, the emergence and development of theory in the form of structural finds meaning. The scientific accuracy of any theory is dependent on the accuracy of the structures and whatever the structures arranged better, theories are more robust. Research Program by Lakatos and "Paradigm" by Kuhn can be raised in line with this research structures.

According to Lakatos scientific statements should be considered in the research program framework. He claimed that most of the technical and social science theories are in a series of cases of (hard core). The hard cores often come in the form of very abstract assumptions that are not empirically testable. But irrefutability of hard cores does not necessarily mean that the theory is irrefutable. If a set of testable predictions can be derived from observations, the theory as a whole can be considered as a theory falsifiable (Marsh and Stoker, 2009: 114). In fact, Lakatos introduced the methodology programs of scientific research assert that a scientific achievement is not a single separate theory, but in fact a research program constitutes the unit. Science is not a simple series of trial and error experiments, and believes Newton's theory of gravity, Einstein's theory of relativity, quantum mechanics, Marxism and all are research programs. A research program according to Lakatos is a structure guides the research outline for future in positive and negative manner (Chalmers, 1994: 119). The first pillar of the research program is its skeleton that is called Hard core (central case) a research program constitutes basic theory and hypotheses the development of an application is subject to the assumptions and the hard core assumptions of the Lakatos irrefutable theory. The second pillar of the research program is the protective belt protecting the hard core assumptions of the program. This belt not only is complementary hypothesis completely clarifying the hard core, but includes hidden assumptions and statements included in observation (Chalmers, 1994: 120). The third pillar of this research program is a falsifiable or liable to revocation assumptions included in the program that these secondary assumptions prevent the hard core assumptions annulment. The fourth pillar of a research program is to predict the future based on a priori proven hypothesis that helps a research program to produce theory for the future. The fifth pillar of a research program is to be able to explore a range of theories and other research programs for the future, it is sustainable, but is degenerating and decaying if not able to do discovered and anticipated new programs in the field of scientific research. Lakatos research program with Popper's falsifiability difference is that firstly, if Popper tried to invalidate the theory, Lakatos tried to save research program. Second, Lakatos 
seeks to provide macro-structures in his research program that forms late, but Popper argued theories were frequently falsified. Third, Lakatos research program is looking for big results while in Popper falsificationism and earlier positivism, the results of theories came to be minor.

The theory of "paradigm" by Kuhn also may be explained in line with the structural development of scientific theories. Kuhn poses theory of paradigm in line with the progress of science and believes that the progress of science is done in stages as follows: Stage before science, conventional science, crisis and revolution, a new conventional science, a new crisis. He believes that unorganized activity that precedes the formation of a science ends with gaining structure and orientation when a given paradigm to see the continuity of the scientific society. A paradigm can be formed of general theoretical assumptions and laws, and techniques for their application, which is accepted by a scientific society. A science comes to fruition with a "paradigm". A paradigm determines a measure of what is officially known within the scientific territory under its control. The paradigm coordinate and guide conventional science that is "answer the question" in the scientific realm. According to Kuhn believes the presence of a powerful paradigm to help a conventional scientific tradition is the property separates science from non-science, so it is a part of the science (Chalmers, 1994: 132). Kuhn knows the general acceptance of a paradigm by the scientific society as a measure of its formation, because he knows scientific study only possible within the paradigm. He calls stage where there is no paradigm with scattered research activities without any settled science as pre-scientific stage. Finally, a paradigm is regular and purposeful being accepted by the scientific society. In other words, a paradigm has the task of regulating scientific activities. The absence of paradigm in a field means to be in the stage of pre-science (Moeini Alamdari, 2006: 44). In fact, Kuhn, with the theory of paradigm, emphasizes on the historical nature of sciences and rejects the claim of positivism and falsification that science is the only way to uncover the truth at any time and place. The essence of his argument is that any perception of the world requires "concepts" and key concepts of a scientific and methodological rules depends on the framework agreement or more broadly, the paradigm that researchers begins to study relied on. When the paradigm is changed, the old concepts and rules will lose its credibility. As a result, in each particular field of science, knowledge paradigm accumulated form special time cannot really represent the absolute knowledge of "reality", because this knowledge is necessarily relative in the event of a change in paradigm (Seyyed Imami, 2008: 37).

The governance of structure over the western theorizing resulted changes in western theorizing and thinking that we know as the postmodernism. Kuhn's paradigm theory raised instability, changes and relativity in the science. Paradigm on the one hand draws the separation between different paradigms that is the "rupture" and on the other hand raised the changes in scientific theories. Because scientific breakthrough literally does not occur by rebuilding theories within the paradigm in theory of paradigm, but with the transition from one paradigm to paradigm, that is the scientific revolution and the scientific revolution is associated with "rapture". However, the scientific revolution is associated with the change in worldview and transformed reality; and the mental structures are fully variable (Seyyed Imami, 2008: 45).

Feyerabend challenges Scientism more in continued this path of study in modern thought. Feyerabend view is more negative, although contains positive points as well. He believes that "anything goes ." This is the only positive principle by Feyerabend's that forms the main Feyerabend theory. Feyerabend impact modernity's ontology with this principle in that the principle (anything goes) breaks down monism of the time in addition to the modern era certainty and positive ideas. Feyerabend in his book "Against Method" elaborates this theory. He said the fact that no methodology has the ability to achieve true science. The main reason but not the only reason is that this methodology does not comply with the history of physics. He criticized the deductive methodology in that these methods are deterministic. While he, in his theory seeks to prove that inductive and scientific methodology fail in the attempt to prepare guidelines useful to help scholars. He believes that opting for this science that has dropped to a few simple methodological rules is a farce, especially if we take into account complexity of its history (Chalmers, 1994: 186). In fact, Feyerabend tries to show different methods and practices can be used to add to human knowledge and any method has its own characteristics and logic. He, to prove that, proposes the theory of "incommensurability", believing that in some cases, the fundamental principles of two rival theories can stand so far away from each other, that formulated the basic concepts of the theory of a so-called theory seems impossible, and concludes that two rival theories do not share any common observation statements and thus it would be impossible to logically compare the two ideas. Furthermore, the logical inference from the results of a theory of the origin of rival theory would be impossible comparison. Therefore, the two theories are not measurable (Chalmers, 1994: 189 and 190). This argument leads him to the principle of "anything goes" with valid recognition in every way and manner deemed and infers diverse recognitions using plural methods.

In fact, with reference to the theory of Lakatos and Kuhn, both were able to find a kind of plurality and break in the paradigm and their research programs. Feyerabend, following this path, put this pluralism and break one step forward and added the relativity of knowledge to it. The postmodernism emerges by Feyerabend but he's not among postmodern thinkers. In fact, his idea is to bridge the transition from the modern to the postmodern world in the realm of scientism ideas. Development of the post-modern theory is the product of an industrial society historical period. This theory 
reflects the ideological positions of the radical faction of Western and non-Western intellectuals in times of political and scientific crises particular to this period. There are many sources of intellectual postmodernism. The intellectuals fascinated by Heidegger critiques of the metaphysical interpretation of Nietzsche's anti-relativistic nature. Some know it as the product skepticism and doubt and ambivalence of post-industrial society. Others know emergence of postmodernism as marker of the completion of the development of capitalist society logic (Alamdari, 2006: 128- 131). "Martha Cooper" calls it a new morals, new forms of dialogue and efforts to achieve a ne w political communication and believes that postmodernism was born out of the need to change political thinking ,given moral and social development of the contemporary post-industrial society that can better respond to the needs of communities and Richard Bernstein calls it one of the most important moments in the history of thought trying to pass Western thought crisis through a Critical thinking (Moeini Alamdari, 2006: 131 and 132). Post-structuralism is postmodernism philosophical arm critique of the modern era centralization thought and avoids mastery of any unit structure on the thought realm; howe ver, this kind of attitude should not be attributed to anti- structuralisms, but post-structuralism merely opposes the absolute and the centrality of the structure.

Overall, postmodernism thinkers and its philosophical side namely post-structuralism have the following features:

1- Criticize the science orientation of positivist approach avoiding it.

2- Simultaneously apply achievements of science and philosophy and try to provide a scientific/philosophical understanding and indeed the metatheory.

3- They are interpretative; in the sense that believes that humans should use to interpretive medium to reach reality and only interpretation are close to reality.

4- They are anti-realism and structure oriented; they believe that reality does not exist and the man is faced with constructions of reality that is created by their mind different for per person.

5- They believe in the fluidity of thought; they are against the certainty of the subject and avoid scientific and philosophical absolutist and see reality as fluid

6- They are Perspectivism and Pluralist; they are oriented toward micro attitudes with attention to numerous comments and views, they avoid macro patterns and fight meta-narratives

7- They cross structuralism (formalism); do not tolerate a unit of structure and form, but follow the local language.

8- They are anti-fundamentalism, and avoid providing the basis and foundation of positivism.

9- They are anti-naturalism; and do not consider any essence for the truth, but rather accept relative interpretations of truth.

10- They are anti-metaphysics; and reject traditional metaphysics.

11- They are anti-epistemology; in the sense that, they believe that reality is not knowable, so any discipline should be imposed to reality, because reality is not detected.

12- They are critic of modernity and challenge modernity, but not anti- modernity, but want to think beyond modernity.

\section{Summary and Conclusion}

All investigated modern empiricist trends and prospects have the same ontological specifications and features. These trends including crude empiricism by Lakatos and Kuhn first look for a solution and then seek to know the solution superior and absolute, but they are both positive and absolute except for Feyerabend who is both positive and negative. The positive and absolutism is featured both classical and modern features. However, within this period we can also find a variety of approaches such as scientism, rationalism, religion orientation, and so on. But this scientism, absolutism, positive and issuing inviolable decree break by Feyerabend and the realm of thought and philosophy steps into a new field of ontological study known as post-modernism era. The post-modernism era also is another turn the view seeking to provide new approaches to advance human knowledge in Western thought with assumptions such as relativism, pluralism, anti-essentialism and avoidance of uncertainty and generality. However, the scientism of modern philosophy in the West tries to apply scientific principles and methods from mathematics in his philosophical attitude in recent decades in approaches such as Instrumental Positivism and Behaviorism .In Iran in recent years, there are researchers used Western modernity (positivism, falsification, the research program, paradigm) to do their research.

\section{References}

Against mothod ouline of an anarchistic theory of knowledge new left books, londres. (1975).

Bacon, F. (1620). novum organum, English translation in R.L. ellis and J. spedding.

Bashiriyeh, H. (2009). The history of political thought in the twentieth century (liberalism and conservatism)", Nashre 
Ney, the ninth edition.

Chalmers, A. F. (1994). "What is science", translated by Mohammad Mashayekhi Publishing Corporation publication, First edition.

Chalmers, A. F. (2008). Nature of Science (Introduction to Scientology philosophical schools), translated by Saeed Zibakalam, Scientific and Cultural Publishing Company, First edition.

Copleston, F. (2006). History of Philosophy (Volume V), translated by Amir Jalal al-din Alam, Scientific and Cultural Soroush Publication, Fifth Edition.

Coser, L. (1990). Masters of Sociological Thought, translated by: Mohsen Solasi, Academic Press, First Edition.

David, H. (Unknown). An inquiry concerning human understanding, p.92

Feyerabend, P. (1996). Against method, translated by: Mehdi Qavam Safari, Fekr-e Roz Press, First edition.

Gillis, D. (2002). Philosophy of science in the twentieth century, translated by Hassan Miandari, SAMT, First edition.

Haqiqat, S. S. (2008). Methodology of Political Science. Mofid University Press, Second edition.

Hume, D. (1888). Treatise on human nature, edited by L.A. Selby- bigge the clorendon press, oxford.

Khorram, S. B. (1999). Logical positivism, Scientific and Cultural Publications, Second edition.

Körner, S. (1988). “Kant's philosophy”, translated by: Ezatollah Foladvand, Kharazmi Press, First edition.

Kuhn, T. (1990). The Structure of Scientific Revolutions, translated by: Ahmad Aram, Soroush Publications, First edition. (Placeholder1).

Lawrence, P. K. (2009). "Extractions of modernism texts", translated by Abdulkarim Rashidians, Nashre ney, $7^{\text {th }}$ Edition.

Marsh, D., \& Gerry, S. (2009). Method and theory in political science, translated by: Amir Mohammad Haji Yousefi, Research Institute for Strategic Studies, Fifth Edition 2009.

Moeini, A. J. (2006). Methodology The new theory in politics (positivism and post-positivism), Tehran University Press, First Edition.

Nozari, H. A. (2006). “The formation of modernity and postmodernity”, Naghshe Jahan, second edition.

Popper, K. (2002). All Life is Problem solving, London: Routledge. Quinn Patton, Michael. Qualitative Research and Evaluation Methods. Third Edition. Thousand oaks, Calif. Sage.

Popper, K. (1968). The logic of scientific discovery, (London: Hutchinson).

Seyyed, I. K. (2008). Research in Political Science (positivist, interpretative and critical approaches), Imam Sadiq University Press, Second edition.

Vaezi, A. (2009). “Review theories of justice”, Imam Khomeini Education and Research Institute, First edition.

\section{Copyrights}

Copyright for this article is retained by the author(s), with first publication rights granted to the journal.

This is an open-access article distributed under the terms and conditions of the Creative Commons Attribution license which permits unrestricted use, distribution, and reproduction in any medium, provided the original work is properly cited. 